\title{
Design and Implementation of Solar Tracker on Solar Panel
}

\author{
Jeffery Ali Rizvi*, Muhammad Ibrar-Ull-Haque*, Jawad Ali Arshad \\ * Department of Electrical Engineering, University of Engineering \& Technology, Peshawar, Pakistan.
}

A BSTRACT

\begin{abstract}
Energy is the necessity having utmost importance, also is a priority factor for the development of modern era countries. Current time calls for bulk of energy supply as various nations are at verge of energy crisis, RE (Renewable Energy) resources like wind systems, solar panels, and tidal wave etc. are the best options available in current era for energy supply. The most abundant resource of RE is solar system which is available from the sun itself. The sun is source of sufficient energy supply and it can be used throughout the year. Electricity generation due to the reduction of fuels is the biggest challenge which will have adverse effects to be faced in upcoming future.

The electricity generation via solar energy is costly. Energy from PV (Photovoltaic) cell depends on solar insulation. Maximum energy extracted from sun by the plane of solar collector should be normal to incident radiation. Improving efficiency by change in design then implement on solar tracker system to collect maximum solar power extraction with association of the panels and the sun itself. System tracks the maximum intensity of light by adjusting the panels to normal to incident light. The sun tracking system uses four light dependent resistors used as a sensor for finding brighter point in the sky. Rotating DC Motor can be controlled via signal and data processing based on micro-controller, by doing so the performance parameters of this system are now dependent on features such as solar radiation, hourly electrical power, maximum gain of energy, additionally short circuit and open circuit current are compared with the fixed tilt solar collector.

Key Words: Solar Efficiency, Dual axis DC Motor, Solar Tracker, Micro Controller, Photovolatic, Light Dependent Resistor, Electrically Erasable Programmable Read-Only Memory.

Author's Contribution

1,2,3 Manuscript writing, Data Collection

Data analysis, interpretation, Conception,

synthesis, planning of research, and

discussion

Cite this article: Rizvi JA, Haqe Muhammad IU, Arshad JA. Design and Implementation

of Solar Tracker on Solar Panel. J. Inf. commun. technol. robot. appl.2020; 11(2):53-56

Address of Correspondence

Jeffery Ali Rizvi

jarizvi@ssuet.edu.pk

Article info.

Received: July 09,2020

Accepted: November 18,2020

Published: December 30,2020
\end{abstract}

\section{INTRODUCTION}

Sun tracker system functions on the principal of orienting a panel towards the sun by making use of LDR (Light Dependent Resistor) which is interfaced to motors [1]. This research proposes an idea of two axis tracking system for solar concentration through the use of solar reflectors [2]. Soteris [3] suggests an idea of a tracking system which can be implemented through one axis. It is used for rotation through a microcontroller to have maximum solar radiation incident onto panel [4]. Double headed threats of energy reduction also global warming demands for the methods of utilizing renewable energy resources at the origin of public interest as indicated through a research, suggestion calls for a system which uses a dual-axis AC motor along with stand-alone PV inverter to achieve the goal of solar tracking [5]. Panels can be moved in both $\mathrm{x}$ and $\mathrm{y}$ axis by aid of DC Motors. In presented paper there is a Dual axis solar tracker which has two degrees of freedom acting as axes of rotation for the panel. Axes are kept normal to each other by rotating simultaneously longitude and latitude, they are also capable of pointing the sun's radiation perpetually [6-7]. By referring another research in which sensing of sun's position is been done through two stages, first stage which is also termed as direct sensing is been performed via aid of set of LDR sensors as output tuning for trimming both the angles which are azimuth and altitude. 
Second stage creates a scenario when the weather is dusty, cloudy or rainy, the tracking system stops so that it stay in the position of the sun but according to Kelly cosine relation the power will decrease according to Iraq - Baghdad city weather where on average 10-15 rainy days are observed in a particular season [8]. This piece of work focuses on sun tracking by taking use of servo motor which is coupled with the solar panel itself. So as to take in account, the bulk of sun light at the incident panel throughout the day at any given time, it is better than method of fixed panel array whose efficiemcy is very low. The microcontroller Arduino (Mode UNO) was being programmed with aid of $\mathrm{C}++$ language where on other hand sun light processing track was implicated by taking use of LDR, Chip IC H-Bridge and microcontroller Arduino (UNO) Circuits are designed with help of software Proteus. By means of doing circuit design and tracking control process of sun, the cost reduction improved majorly and ample of energy was saved upon final implementation of system [9].For maximum power output (approximately 40\% gain) as shown in Fig. 1.

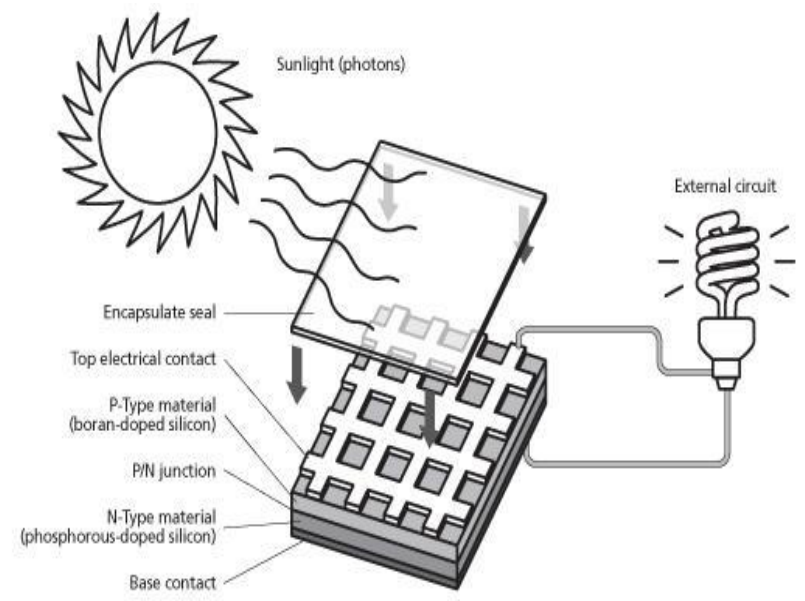

\section{FIG. 1 Working of A PV-Cell on Panel}

\section{Operation and Working}

Operational feature of proposed work is to track maximum amount of solar radiation which converts the light energy into electrical energy. As the idea consists of dual axis formation, so it automatically starts working when light comes incident to the solar tracker/LDRs. Two main features of the system are manual and automatic mode. Additionally, having the ability to sense alarming situations like storm and windy conditions where panel positions itself to 180 olikewise is the feature of night mode, In rainy conditions the panel automatically set to $90^{\circ}$, At night mode the panels are set at reset mode so it can starts working when sun rises from the east. Table 1 show parameters used on solar cell including output power, maximum voltage and current, open and short circuit voltage, module efficiency. Algorithm of operation is shown in Fig. 2 which explains the rotation of panel upon receiving feedback from controller after detection of sun's location. If the sun is at position $X$ as indicated then motor derives the panel to $\mathrm{X}$ location, vice versa for position $\mathrm{Y}$.

\begin{tabular}{lcc}
\hline \multicolumn{4}{l}{ Table I: Parameters of The Used Solar Cell } \\
\hline Nominal Peak Power & $W_{\mathrm{p}}$ & $295 \mathrm{~W}$ \\
\hline Output power tolerance & $\mathrm{W}_{\mathrm{p}}$ & $0-+3 \%$ \\
\hline Maximum Power Voltage & $\mathrm{V}_{\mathrm{mpp}}$ & 32.73 \\
\hline Maximum Power Current & $\mathrm{Impp}_{\mathrm{mp}}$ & 9.04 \\
\hline Open-Circuit Voltage & $\mathrm{V}_{\mathrm{oc}}$ & 40.12 \\
\hline Short-Circuit Current & $\mathrm{I}_{\mathrm{sc}}$ & 9.53 \\
\hline Module Efficiency & $\mathrm{H}_{\mathrm{m}}$ & 17.75 \\
\hline
\end{tabular}

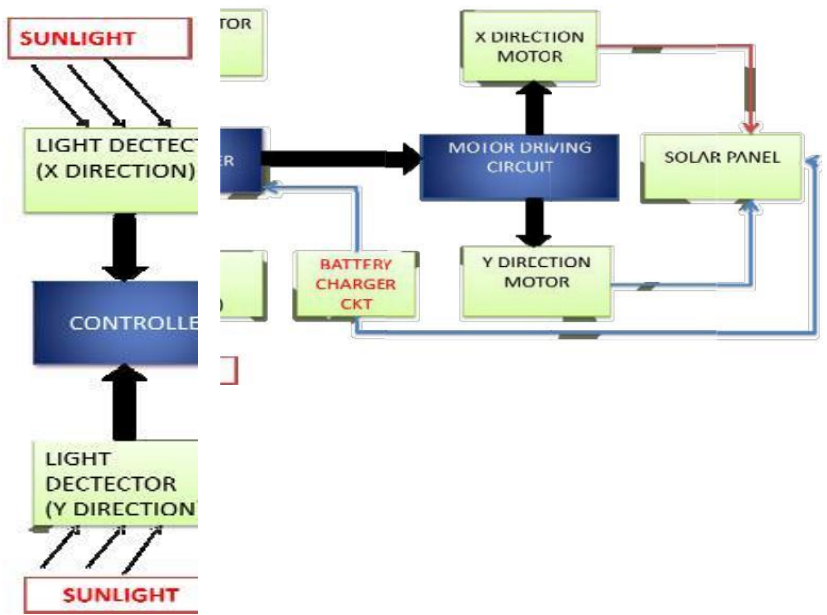

Fig. 2. Algoritham for operation

\section{System Software and Hardware}

Software implementation was done by aid of lab view, which has vast variety of commands and features, buildup of soft tools became much easier when using this particular software, as state diagram in Fig. 3 depicts the auto axis detection of sun when it comes to hardware the majority of work is hardware based as the assembly of tracker along with panel takes a whole new horizon of mechanics, the mechanical alignment as shown in Fig. 4 is tiled upwards as to face the sun with particular angle on startup. 


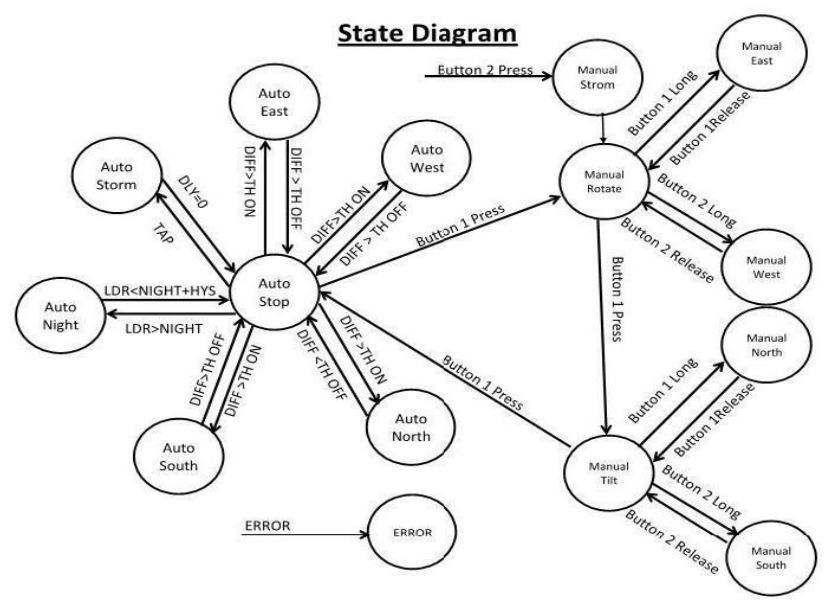

Fig. 3. State Diagram of Operation

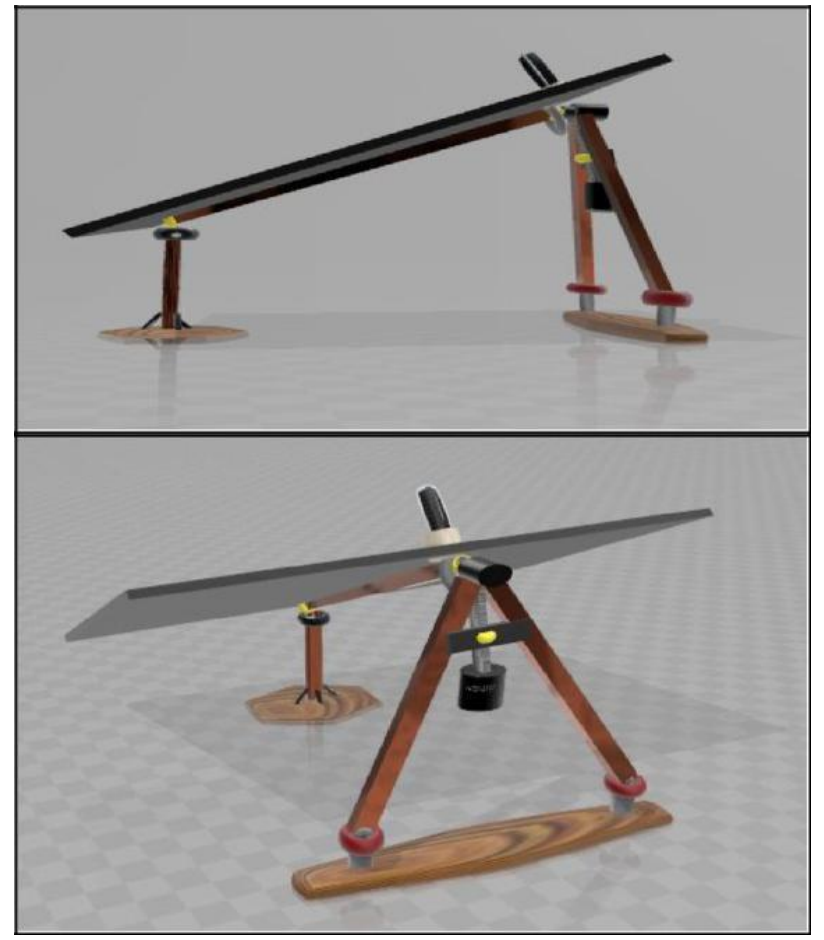

Fig. 4. Complete structure

\section{RESULT}

The sun position that is azimuth and height position of sun are appeared in figure which is computed from Sun Position Calculation.

Table II and Fig. 5 depict both the static and tracking panel power for every changing hour several times in a day. Static Results were taken on 25oangle. Dynamic tracking power has been measured by Current Sensor and a voltage divider circuit controlled by ATmega328 Ardunio mini. The results were then saved in EEPROM (Electrically Erasable Programmable Read-Only Memory). Fig. 5 which is a bar chart replicates the Table II results which were observed in sense of measuring static and tracking power, after observation it was found that power values in 1st half of day were on higher end where as on contradiction power consumption in 2 nd half of day is reduced.

\begin{tabular}{llll}
\hline \multicolumn{4}{l}{ Table II: Static, tracking and power gained } \\
\hline $\begin{array}{l}\text { Time } \\
\text { (Hours) }\end{array}$ & Static Panel Power & $\begin{array}{l}\text { Tracking Panel } \\
\text { Power }\end{array}$ & $\begin{array}{l}\text { Power Gained by } \\
\text { Tracking Panel (\%) }\end{array}$ \\
\hline $08.00 \mathrm{am}$ & 067.14 & 144.19 & 114.76 \\
\hline $09.00 \mathrm{am}$ & 128.37 & 174.03 & 035.57 \\
\hline $10.00 \mathrm{am}$ & 135.53 & 183.33 & 035.27 \\
\hline $11.00 \mathrm{am}$ & 149.99 & 192.63 & 028.43 \\
\hline $12.00 \mathrm{pm}$ & 170.85 & 021.89 & 026.95 \\
\hline $01.00 \mathrm{pm}$ & 167.79 & 200.71 & 019.62 \\
\hline $02.00 \mathrm{pm}$ & 155.37 & 183.33 & 018.00 \\
\hline $03.00 \mathrm{pm}$ & 102.13 & 141.98 & 039.02 \\
\hline $04.00 \mathrm{pm}$ & 068.35 & 075.37 & 010.27 \\
\hline $05.00 \mathrm{pm}$ & 034.25 & 042.39 & 023.77 \\
\hline
\end{tabular}

\section{Static And Tracking Comparision}

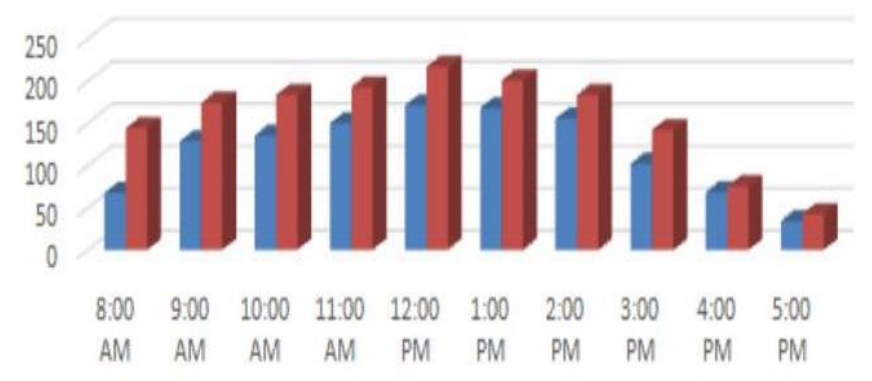

\section{- Static Panel 【racking Panel}

Fig. 5. Static and Tracking Comparison

\section{CONCLUSION}

In depth analysis made us realize that our proposed idea may facilitate and contributions for the cause of solar energy applications. Simplified yet economical control implementation, added with a stand-alone PV inverter to empower the entire system, having ability to maneuver both simultaneously with in their respective boundaries, ability to adjust accuracy of tracking, and also being applicable of platform moving along with solar tracker. Successful achievement of desired goals are observed after testing the panel rotation on required angles and attaining output approximately near to the target

\section{FUTURE WORK}

Future enhancement is to add auto dust cleaning system which will be used for dust cleansing from solar panel. If dust stays on surface of panel it will diminish the energy output of solar panel about 
$15 \%$.Another advancement is to get the output on your smart phone using an application and also to control the movements of tracker manually with your smart phone. More sensitive Photo resistors may be used which help to track sun light more efficiently.

Acknowledgement: Firstly worth mentioning is the name of Almighty ALLAH For his countless Blessings that he showered on us, by aid of which we have achieved the completion of this research Work in the bests regards. Profound positive vibe achieved from management of university whose guidance and monitoring was again of utmost help. Additional vote of thanks to those who rendered their support to us during the whole phase of research work.

\section{REFERENCES}

1. Sadeque, F., "Design and Implementation of Automated Solar Tracking System", B.Sc. Thesis, Bangladesh University of Engineering \& Technology, Dhaka, Bangladesh, June, 2014.

2. Agarwal, A.K., "Two Axis Tracking System for Solar Concentrators", Renewable Energy, Volume 2, Issue, 2, pp. 181-182, New Delhi, India April, 1992.

3. Soteris, A.K., "Design and Construction of a One-Axis SunTracking System", Solar Energy, Volume 57, Issue, 6, pp. 465-469, Cyprus, December, 1996.
4. Lee, C.-Y., Chou, P.-C., Chiang, C.-M., and Lin, C.-F., "Sun Tracking Systems: A Review", Sensors (Basel). Volume 9, No. 5, pp. 3875-3890, Switzerland, May, 2009.

5. Wang, J.-M., and Lu, C.-L., "Design and Implementation of a Sun Tracker with a Dual-Axis Single Motor for an Optical Sensor-Based Photovoltaic System", Sensors (Basel), Volume 13, No. 3, pp. 3157-3168, March, 2013.

6. Wei, C.-C., Song, Y.-C., Chang, C.-C., and Lin, C.-B., "Design of a Solar Tracking System Using the Brightest Region in the Sky Image Sensor", Sensors, Volume 16, No. 12, [DOl: 10.3390/s16121995], November, 2016.

7. Donald A. Neamen, "Semiconductor Physics and Devices: Basic Principles", Volume 3 pp. 514-515, October 10, 2018

8. Mustafa, F.I., Shakir, S., Mustafa, S., and Naiyf, A.T., "Simple Design and Implementation of Solar Tracking System Two Axis with Four Sensors for Baghdad City", 9th International Renewable Energy Congress, pp. 1-5, Hammamet, Tunisia, 2018

9. Muthna, J.F., Fayadh, R.A., and Mousa, K.W., "Design and Implementation of Smart Electronic Solar Tracker Based on Arduino", TELKOMNIKA, Volume 17, Issue, 5, pp. 2486-2496, Yogyakarta, Indonesia October, 2019. 